UDC 004.942:519.876.5

DOI: $10.20535 /$ SRIT.2308-8893.2021.4.10

\title{
ON ONE APPROACH TO USING OF FRACTIONAL ANALYSIS FOR HYBRID MODELING OF INFORMATION DISTRIBUTION PROCESSES
}

\author{
E.V. IVOKHIN, L.T. ADZHUBEY, YU.A. NAUMENKO, M.F. MAKHNO
}

\begin{abstract}
The article discusses a technique for constructing a model and a method for finding solutions in the problem of imitating the process of information dissemination based on the use of a boundary value problem for a fractional differential equation in partial derivatives. It is proposed to use the analogy technique for modeling information dissemination processes, which is based on the use of the features of a fractional analysis and the diffuse nature of information penetration processes. A method for constructing hybrid models is proposed, which makes it possible to take into account changes in the interval of values of the spatial variable over time. Homogeneous and inhomogeneous models of diffusion processes are considered, which make it possible to numerically obtain and analyze experimental data for solving problems of monitoring the levels of information dissemination in social groups.
\end{abstract}

Keywords: information, dissemination, modeling, diffusion hybrid models, fractional analysis.

\section{INTRODUCTION}

The study of real processes and phenomena by methods of mathematical modeling using a strictly deterministic approach is associated with significant limitations. In many cases, the systems and processes under consideration possess unusual properties of fractality due to the complex geometric structure of the surface, self-similarity of sets and media, inhomogeneity of dynamic characteristics, and the presence of the effect of heredity. The theory of fractals has found application in describing the geometric properties of complex objects, in the analysis and forecasting of the behavior of dynamic systems and processes. At the same time, to simulate the dynamics of processes and phenomena in fractal systems, one often resorts to the apparatus of fractional-differential calculus. A fractional derivative with respect to time is used to indicate that a given process has memory, and a fractional derivative with respect to a coordinate is used to indicate that the process takes place in a self-similar inhomogeneous medium. The processes of heating solids in non-equilibrium conditions or the diffusion of impurities in the soil, the spread of heat in highly porous media also have properties inherent in fractals. For example, work [1] describes a fractional differential approach for modeling a wide class of problems in the theory of heat and mass transfer: heat transfer in inert media, isothermal processes of mass transfer, mass transfer at the contact boundary of moving media, heat transfer in the presence of nonlinear heat release. In [2], a mathematical model of anomalous diffusion is presented in the form of a partial differential equation of mixed order. The work [3] describes a model of systems with memory, provides a mathematical formalization of the work of real elements of electrical circuits. In 
work [4], generalized equations of diffusion and drift of charge carriers in disordered semiconductors for dispersive transfer were obtained. Unfortunately, not all differential equations with fractional derivatives can be solved on the basis of analytical methods and approaches, since they are developed for a limited class of problems. In this case, numerical solution methods are used more often $[5,6]$. Despite the problems of use, modern research on modeling problems is often based on the use of fractional analysis and its intensive implementation for solving problems in various fields of knowledge. Using fractional integrodifferentiation or fractional analysis, one can write out adequate mathematical models of social, natural, economic and other processes [7]. In accordance with the new interpretation of the experimental data, the model parameters make it possible to more accurately approximate the obtained data and provide information on the properties of the research object based on the solutions of the corresponding nonlocal equations. It should be noted that the use of differential equations of fractional order, on the one hand, leads to the need to solve an infinite number of differential equations, and, on the other hand, allows one to obtain a set of solutions corresponding to them and to consider various functional spaces. This diversity also allows to improve the adequacy of mathematical models. The problems of formalizing and studying the development in time of the processes of information dissemination and influence on society are one of the most important, requiring the use of a fundamentally new toolkit, which should allow to adequately reflect the state of the dynamic component of the information dissemination process [8].

At the same time, when developing new approaches, the adaptation of classical methods of analysis and processing of dynamic processes is often used, which is based on the use of the analogy method [9-11]. It is obvious that the dissemination of information in society, thoughts about social networks, advertising products and other information processes are in many ways similar to the processes of distribution (penetration) of a substance that spreads in a certain environment. It is assumed that the environment is homogeneous and the area of admissible distribution of information can be calculated based on the structural extension of the basic model by a hybrid subsystem [9]. This hybrid model turned out to be quite effective for describing the states of various target groups of people affected by the information flow [11].

\section{FORMALIZATION OF THE INFORMATION DISSEMINATION PROCESS BASED ON HYBRID DIFFUSION MODELS}

One of the approaches, within the framework of which both the classical and the system method of modeling the behavior of objects (systems) is effectively implemented, is a method based on the application of formal (biological, chemical or physical) analogies in the process of dynamics formalizing $[8,9,12]$. The practical application of the analogy method begins with the development of the first approximation of the model and consists in converting the mechanistic analogue to the mathematical model of the process under study. The next stage involves the use of mathematical tools to analyze the model. The mathematical results obtained in the process of computational experiments go through the subsequent stage of reverse interpretation in terms of the analogy system. And finally, it is necessary to evaluate the results obtained on the basis of the model in order to decide whether they are satisfactory - formally substantiated and sufficient to achieve the goals. 
The tasks of the analytical processing of modern information flows and their influence require solving the problems of studying the dynamics of information dissemination processes based on simulation and forecasting tools. The development of models and methods for simulating information impacts, taking into account the processes of information dynamics, can effectively solve important communication problems, significantly increase the level of information security of the state, and tactically and strategically predict the development of information confrontation events. A constructive method for analyzing the dynamics of information dissemination processes can be proposed based on the use of a fundamentally new toolkit using the method of analogy and hybrid models, which allows adequately reflecting the state of the dynamic component of the process of disseminating information [10,11,13-17].

We will model changes in the level (concentration) of information in a population with the help of the diffusion equation [18], assuming that this process is similar to the spread of a substance (infection) over a specific time period $t \in[0, T]$ and can be described by a scalar equation with Kaputo-Gerasimov fractional derivative [18] of order $\alpha, 0<\alpha<1$,

$$
D_{0 t}^{\alpha} u(x, t)=-k(t) \partial^{2} u(x . t) / \partial x^{2},
$$

where $D_{0 t}^{\alpha} f(z)=1 / \Gamma(1-\alpha) d / d z \int_{0}^{z} f(s) /(z-s)^{\alpha} d s, \Gamma(v)=\int_{0}^{\infty} s^{v-1} e^{-s} d s-$ gammafunction, with boundary conditions in the form $u_{x}^{\prime}(0, t)=u_{0}(t), u_{0}(t) \geq 0-$ given function, $u_{x}^{\prime}(1, t)=0, t \in[0, T]$, and initial condition $u(x, 0)=0,0 \leq x \leq 1$, $D_{0 t}^{0} f(t) \equiv f(t)$.

We believe that the contingent of the target population is formed of 3 subgroups based on the perception of information. We identify the part of the population that is sensitive to the influence of information $y_{1}(t)$, the part which is already under the influence of information $y_{2}(t)$ and the part which is indifferent to information influence $y_{3}(t)$. Then, using the Bailey model [19], the dissemination of appearance information:

$$
\begin{gathered}
\dot{y}_{1}(t)=-y_{1}(t) y_{2}(t) ; \\
\dot{y}_{2}(t)=y_{1}(t) y_{2}(t)-y_{2}(t) ; \\
\dot{y}_{3}(t)=y_{2}(t),
\end{gathered}
$$

with the initial condition $y_{1}(0)=y_{1}^{0} ; y_{2}(0)=y_{2}^{0} ; y_{3}(0)=y_{3}^{0}$, where the total of cure and disease rates are considered to be $1, y_{1}(t)+y_{2}(t)+y_{3}(t)=1, t \geq 0$, there a system of differential equations that describes the process of information dissemination in the target population can be written. Their solutions determine the dynamics of the rate values of individual subgroups.

With such assumptions, the maximum threshold value of $x_{\Gamma}, 0 \leq x_{\Gamma}(t) \leq 1$, will depend on the time, so we have $0 \leq x \leq x_{\Gamma}(t), x_{\Gamma}(t)=y_{1}(t)+y_{2}(t)$, where $y_{1}(t), y_{2}(t)$ - are the components of the solution of system (2). 


\section{MODELING OF INFORMATION DISTRIBUTION PROCESSES (HOMOGENEOUS DIFFUSION)}

The applied study of the obtained model (1) - (2) in the general case is very complex. In order to analyze the constructiveness of the proposed approach, we consider some partial cases. Assume that the level of information dissemination in the group is initially zero. After that, the members of the group have some external influence of information content, which at any time $t \in[0, T]$ is characterized by a constant speed $u_{x}^{\prime}(0, t)=u_{0}(t) \geq 0$.

Given the cumulative nature of the information dissemination process in society, we will search for a partial solution of the diffusion equation (1) in the form

$$
u(x, t)=\int_{0}^{x} X(\xi) d \xi+a t,
$$

where the parameter $a$ for the impact over time for each point in time $t$ is considered proportional to the rate of change of magnitude $x_{\Gamma}(t)$, i.e. $a=\eta \dot{x}_{\Gamma}(t)$, $\eta>0$.

To find solutions, we will assume that the instantaneous value of the coefficient of information penetration $k(t)$ will be proportional to the rate of change of the part of the population that is considered to be susceptible to the influence of external information, i.e.

$$
k(t)=\mu \dot{x}_{\Gamma}(t), \mu>0 .
$$

It is impossible to obtain an analytical form of the Kaputo-Gerasimov fractional derivative, which is written in the left part of equation (1), for an arbitrarily given function $u(x, t)$. However, to find the value of the derivative, you can use different numerical methods [18]. In our case, to study the solutions of the diffusion equation, we consider a partial case for which a fractional derivative can be calculated.

It is easy to verify that $D_{0 t}^{\alpha} t^{\alpha}=\frac{1}{\alpha \Gamma(1-\alpha)} \int_{0}^{\infty} \frac{s^{1 / \alpha}}{\left(s^{1 / \alpha}+1\right)^{2}} d s$, where the improper integral coincides on the basis of comparison $O^{*}\left(1 / s^{1 / \alpha}\right), 0<\alpha<1$, i.e. the fractional derivative has a finite value, the diffusion equation (1) is correct and has a solution for arbitrary $\alpha, 0<\alpha<1$.

Let $\alpha=0,5$. Then, omitting the cumbersome details of transformations and substitutions and taking into account that $\Gamma(0,5)=\sqrt{\pi}$, we obtain the value of the fractional derivative $D_{0 t}^{1 / 2} t^{1 / 2}=\sqrt{\pi} / 2$.

Taking into account the assumptions made about the solution, we will rewrite the boundary conditions of model (1) in the form $u_{x}^{\prime}(0, t)=$ $=(\eta \sqrt{\pi} / 2 \mu) x_{\Gamma}(t), u_{x}^{\prime}(x, t)=0, x_{\Gamma}(t) \leq x \leq 1, t \in[0, T]$.

It is clear that in this formulation, diffusion equation (1) has a special solution that can be obtained provided $x_{\Gamma}(t)=c, c$-some constant, $c \in[0,1]$. In other words, with the presence of a stationary process in the dynamics of the size of the contingent under the influence of information, the level of information dissemination in the group remains constant. This solution is trivial. 
Supposing that $\dot{x}_{\Gamma}(t) \neq 0$ we have that at any given time $t \in[0, T]$ the diffusion equation has a partial solution of the form (3), for which the next ordinary first-order differential equation must be solved

$$
d X(x) / d x=(\eta \sqrt{\pi} / 2 \mu),
$$

with the initial condition at the end of the interval $X\left(x_{\Gamma}(t)\right)=0$. The solution of this equation will be the function $X(x)=\eta \sqrt{\pi} / 2 \mu\left(x_{\Gamma}(t)-x\right), 0 \leq x \leq x_{\Gamma}(t)$, for which the value $X(0)=\eta \sqrt{\pi} / 2 \mu\left(x_{\Gamma}(t)\right)$ is corresponding to the first boundary condition of the diffusion equation.

So, finally, for the arbitrary $\eta>0$ and $\mu>0$ equation (1) with the fractional derivative for $\alpha=0,5$ has the solution of the form

$$
u(x, t)=\eta\left(\sqrt{\pi} / 2 \mu\left(x_{\Gamma}(t)-x / 2 x\right)+\dot{x}_{\Gamma}(t) t^{1 / 2}\right),
$$

which at any time $t \in[0, T]$ determines the level of distribution of information within a subgroup $0 \leq x \leq x_{\Gamma}(t)$, the size of which is a fraction $x_{\Gamma}(t)$ of the total number of members of the group calculated by the system solutions (2) (below the values $x_{\Gamma}(t), \dot{x}_{\Gamma}(t)$ we consider the instantaneous values of magnitude $x_{\Gamma}(t)=$ $=y_{1}(t)+y_{2}(t)$ and its velocity which is obtained from (2) at any moment of time $\left.t\right)$.

This solution may be generalized. It follows from the initial conditions of system (2) that $x_{\Gamma}(0)=1$. This allows you to rewrite the layout of the solution $u(x, t)$ subject to the initial condition $u(x, 0)=0,0 \leq x \leq 1$ from diffusion equation (1).

Indeed, the function

$$
u(x, t)=\eta\left(x \sqrt{\pi} / 2 \mu\left(x_{\Gamma}(t)-x / 2 x\right)+\dot{x}_{\Gamma}(t) t\right)\left(1-x_{\Gamma}(t)\right),
$$

satisfies equation (1) and the initial and boundary conditions, which makes it possible to consider it as a general solution of the diffusion equation (1) for $\alpha=0,5$.

Fig. 1 shows examples of spatio-temporal distribution of levels of information perception within a given target group, which is calculated on the

The behavior of the solution of the diffusion The behavior of the solution of the diffusion equation (excluding the factor $\left(1-x_{\mathrm{r}}\right)$ )

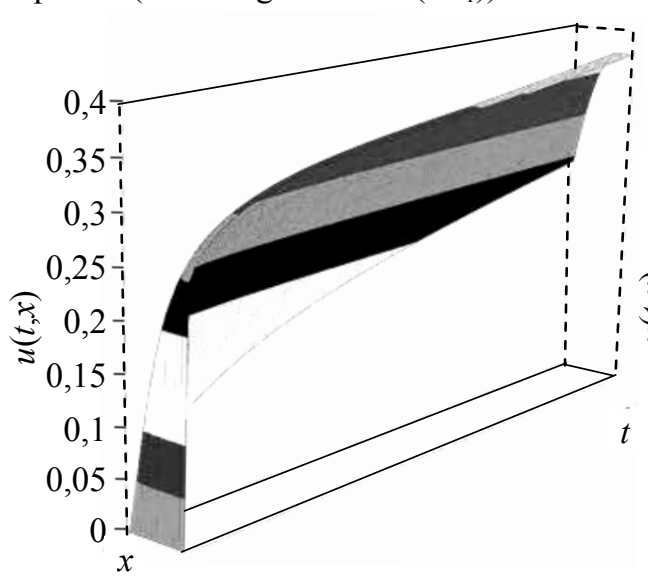
equation (taking into account the factor $\left(1-x_{\mathrm{r}}\right)$ )

Fig 1. Distribution of levels of perception of information in the target group over time (coefficients $\eta=0,1 ; \mu=0,2$ ) 
basis of a hybrid model (1)-(2), obtained by diffusion equation (1) with a fractional derivative Kaputo-Gerasimov order $\alpha=0,5$ and use of the system (2).

\section{MODELING OF INFORMATION DISTRIBUTION PROCESSES (INHOMOGENEOUS DIFFUSION)}

It is clear that this approach can be extended to the case of inhomogeneous diffusion equations. For example, we can consider a generalization of the model proposed in [14], which examines the case of diffusion in an environment that is under external information and which changes over time (for example, in the form of group attitudes to the quality or content of information). In this case, it is said that such an environment "moves" at a constant speed, which is also assumed to be proportional to the change in the number of covered members of the group. This assumption is quite acceptable if we assume a low (which can be neglected) level of intragroup information exchange and consider as the main factor the external influence on the level of information dissemination in the target group. In this case, the diffusion process must satisfy Nernst's law [20], according to which the model has the form

$$
D_{0 t}^{\alpha} u(x, t)=-k(t)\left(\partial^{2} u / \partial x^{2}\right)-\sigma(\partial u / \partial x) .
$$

Here $\sigma$ is the velocity of the medium, $u_{x}^{\prime}(0, t)=0,5 \sqrt{\pi} \frac{\eta}{\omega}\left(\exp \left(\omega / \mu x_{\Gamma}(t)\right)-1\right)$, $u_{x}^{\prime}(x, t)=0, x_{\Gamma}(t) \leq x \leq 1, t \in[0, T]$. Based on this law, the level of information (concentration) $q(x, t)$ that penetrates from the external environment can be calculated based on the interrelations $q(x, t)=-\sigma \partial u / \partial x, \sigma=\omega \dot{x}_{\Gamma}(t), 0 \leq \omega \leq 1$.

Put, as in the previous case, $\alpha=0,5$. Writing the partial solution of the inhomogeneous diffusion equation (4) in the form (3) for each moment of time $t \in[0, T]$, we obtain an inhomogeneous first-order differential equation

$$
0,5 \sqrt{\pi} \eta \dot{x}_{\Gamma}(t)=-\mu \dot{x}_{\Gamma}(t) X^{\prime}(x)-\omega \dot{x}_{\Gamma}(t) X(x),
$$

in which the value $\dot{x}_{\Gamma}(t)$ is considered as the instantaneous value of the rate of change of the value $x_{\Gamma}(t)$, which can be obtained from (2) for each time $t$.

Assuming that $\dot{x}_{\Gamma}(t) \neq 0$, equation (5) can be rewritten as

$$
\mu X^{\prime}(x)+\omega X(x)=-0,5 \eta \sqrt{\pi},
$$

with the initial condition at the end of interval in form $X\left(x_{\Gamma}(t)\right)=0$.

The solution to this equation is a function $X(x)=0,5 \sqrt{\pi} \frac{\eta}{\omega} \times$ $\times\left(\exp \left(\omega / \mu\left(x_{\Gamma}(t)-x\right)\right)-1\right)$, from where we obtain a relationship $X(0)=$ $.=0,5 \sqrt{\pi} \frac{\eta}{\omega}\left(\exp \left(\omega / \mu\left(x_{\Gamma}(t)-x\right)\right)-1\right)$, that meets the first boundary condition of the inhomogeneous diffusion equation (4).

Thus, applying model (4) to describe the process of information propagation in the conditions of external information influence, which changes over time, for arbitrary $\eta>0, \mu>0, \omega>0$, we obtain the solution of equation (4): 


$$
u(x, t)=0,5 \sqrt{\pi}\left(\eta \mu / \omega^{2}\right) \exp \left(\omega / \mu x_{\Gamma}(t)\right)(1-\exp (-\omega / \mu) x)-0,5 \sqrt{\pi} \frac{\eta}{\omega} x+\eta \dot{x}_{\Gamma}(t) t^{1 / 2},
$$

that to provide the initial condition can be generalized in the form

$$
\begin{gathered}
u(x, t)=\left(\left(\eta \mu \sqrt{\pi} / 2 \omega^{2}\right) \exp \left(\omega / \mu x_{\Gamma}(t)\right)(1-\exp (-\omega / \mu))-(\eta \sqrt{\pi} / 2 \omega) x+\eta \dot{x}_{\Gamma}(t) \sqrt{t}\right), \\
\left(1-x_{\Gamma}(t)\right),
\end{gathered}
$$

and which at any time $t \in[0, T]$ determines the level of distribution of information within a subgroup $0 \leq x \leq x_{\Gamma}(t)$, the size of which is a fraction $x_{\Gamma}(t)$ of the total number of group members, calculated using the solutions of the system (2).

Fig. 2 shows examples of the distribution of levels of information impact in the target group, calculated on the basis of solutions of the diffusion model of the form (4).

The behavior of the solution of the diffusion The behavior of the solution of the diffusion equation (excluding the factor $\left.\left(1-x_{\Gamma}\right)\right)$
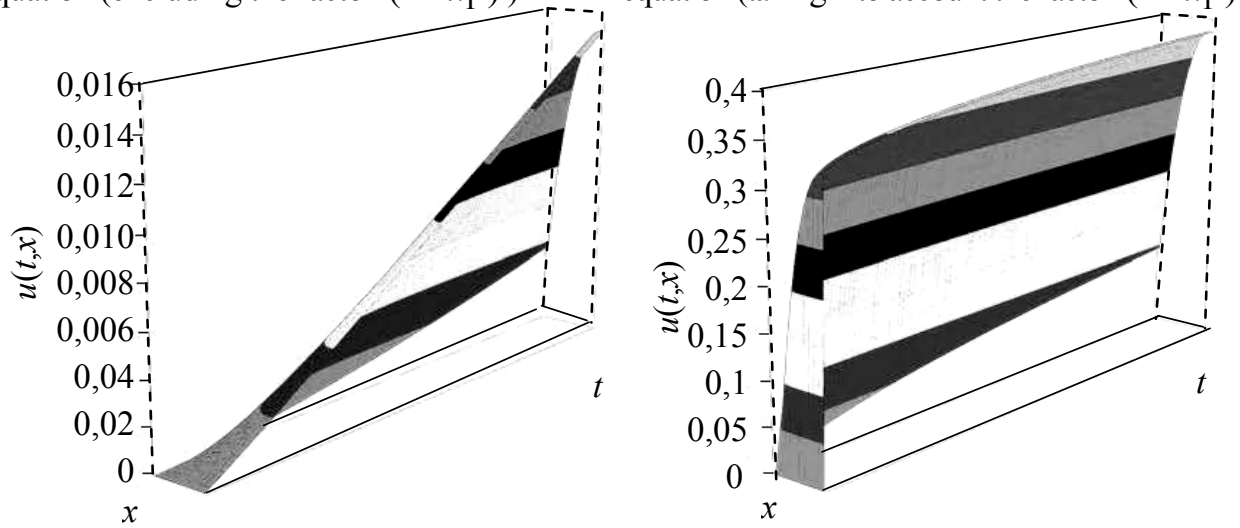

Fig. 2. Distribution of levels of perception of information, which changes in time, in the target group with the external information influence (coefficients of proportionality $\eta=0,1, \mu=0,2, \omega=0,2$ )

\section{CONCLUSIONS}

This paper proposes an approach to the construction of hybrid mathematical models of the dynamics of information processes propagation in the target population, taking into account and without taking into account the impact on the process of information dissemination by external sources and other means.

Formalization is based on the idea of using hybrid mathematical models, which consist of the diffusion (penetration) equation based on a fractional differential equation in partial derivatives and dynamic models, that describe the processes of change in the size of the contingent of the information dissemination environment. A scalar solution for a one-dimensional representation of a group contingent is considered. Various cases of formalization of external influence on the process of information dissemination are considered.

Examples of numerical experiments to evaluate the level of impact based on the application of this approach are given, and their results are analyzed. The comparative analysis allows to confirm the existence of sufficient adequacy of model data and data obtained as a result of real observations of the processes of change in the perception of information within specific target population groups.

The scientific novelty of obtained results is that the proposed technique allows us to describe the levels of propagation, influence and storage of information in a group on the basis of the solution of the diffusion equation, the 
variation of the propagation intervals in which is determined by the additional relationships obtained from the solutions of the additional differential equation (for example, Bailey model (2)).

The practical significance of obtained results is that the proposed methodology form the basis for the development of the applied research project for the analysis of the distribution processes and the influence of information flows in social networks. The development of methods and approaches to support decision making in this direction is an important task that have being solved with the aim of testing concepts and technological solutions in the field of constructive assessment of the dynamics of information impact without creating physical analogues.

In our opinion, the proposed options for hybrid systems of the dynamics of the distribution of information levels based on the diffusion equation using special dynamic models are of certain interest and can be further refined taking into account new formal and informal relationships that use various ways of formalizing the external information influence.

Prospects for further research are the development of new diffusion-type models that formalize the different nature of the influence of external factors on the processes of information dissemination, the study of the influence of delay and impulsive effects on the information process.

\section{REFERENCES}

1. Ю.И. Бабенко, Метод дробного дифференцирования в прикладных задачах тепломассобмена. СПб.: НПО «Профессионал», 2009, 584 с.

2. В.В. Васильев и Л.А. Симак, Дробное исчисление и аппроксимаџионные методы $в$ моделировании динамических систем. Киев: НАН Украины, 2008, 256 с.

3. I. Petras, Fractional nonlinear systems: modeling, analysis and simulation. HEP, Springer, Nonlinear Physical Science, 2011, 235 p.

4. Р.Т. Сибатов и В.В. Учайкин, “Дробно-дифференциальная кинетика переноса заряда в неупорядоченных полупроводниках", Физика и техника полупроводников, т. 41, вып. 3, с. 346-351, 2007.

5. K. Diethelm, N.J. Ford, A.D. Freed, and Yu. Luchko, "Algorithms for the fractional calculus: a selection of numerical methods", Comput. Methods Appl. Mech. Eng., vol. 194, pp. 743-773, 2005.

6. А.Н. Корчагина и Л.А. Мержиевский, “Численное моделирование диффузионных процессов в фрактальных средах”, Ученые записки ЗабГУ, №3(50), с. 53-59, 2013.

7. Л.И. Мороз, “Численное решение одного класса начально-граничных задач для уравнения диффузии дробного порядка", Вестник АмГУ, вып. 85, с. 3034, 2019.

8. R. Bellman, Mathematical methods in medicine. Singapore: World Scientific Pub. Co. Inc., 1983, $268 \mathrm{p}$.

9. A. Nowak and R.R. Vallacher, "Computational Models of Social Processes", Encyclopedia of Cognitive Science, pp. 81-84, 2006. doi: 10.1002/0470018860.s00639.

10. H. Quastler, The emergence of biological organization. New Haven and London: Yale University Press, 1964, 83 p.

11. H. von Scheel, M. Zakaria, and M. von Rosing, "Social Media and Business Process Management", The Complete Business Process Handbook. Body of Knowledge from Process Modeling to BPM, vol. I, pp. 381-398, 2015. doi: 10.1016/B978-0-12-799959-3.00018-5.

12. R. Smith, Modelling Disease Ecology with Mathematics. Ottawa: American Institute of Mathematical Sciences, 2017, 291 p.

13. E.V. Ivokhin and L.T. Adzhubey, "About the use of diffusion process models for description of information extension dynamics", Scientific Bulletin of Uzhgorod University. Series of Mathematics and Informatics, no. 1(34), pp. 86-93, 2019. doi: 10.24144/2616-2019.1(34).

14. E.V. Ivokhin and Yu.A. Naumenko, "On Formalization of Information Dissemination Processes Based on Hybrid Diffusion Models", Journal of Automation and Information Sciences, vol. 50, no. 4, pp. 121-128, 2018. doi: 10.1615/JAutomatInfScien.v50.i7.70 
15. E.V. Ivokhin, L.T. Adzhubey, and E.V. Gavrylenko, “On the Formalization of Dynamics in Information Processes on the Basis of Inhomogeneous One-Dimensional Diffusion Models", Journal of Automation and Information Sciences, vol. 51, no. 2, pp. 22-29, 2019. doi: 10.1615/JAutomatInfScien.v51.i2.30

16. E.V. Ivokhin and L.T. Adzhubey, "On the modeling of information distribution dynamics on the basis of homogeneous diffusion hybrid models", Scientific Bulletin of Uzhgorod University. Series of Mathematics and Informatics, no. 2(35), pp. 112-118, 2019.

17. E.V. Ivokhin, L.T. Adzhubey, E.V. Gavrylenko, and Yu.A. Naumenko, "Research of dynamics of information distribution processes based on diffusion hybrid models", Radio Electronics, Computer Science, Control, no. 2, pp. 129-136, 2020.

18. Р.И. Паровик, П.П. Фирстов, и Е.О. Макаров, “Математическое моделирование фрактальной размерности геосреды", Вестник КРАУНЦ. Физ.-мат. науки, вып. 2(3), c. 42-49, 2011.

19. E. Hairer, S.P. Norsett, and G. Wanner, Solving Ordinary Differential Equations I: Nonstiff Problems; (2nd ed.). Berlin: Springer-Verlag, 1993, 512 p. doi: 10.1007/978-3-54078862-1

20. Б.М. Будак, А.А. Самарский, и А.Н. Тихонов, Сборник задач по математической физике. М.: ГизТТЛ, 1956, 683 с. doi: 10.1016/С2013-0-05314-5

Received: 08.07.2021

\section{INFORMATION ON THE ARTICLE}

Eugene V. Ivokhin, ORCID: 0000-0002-5826-7408, Taras Shevchenko National University of Kyiv, Ukraine, e-mail: ivohin@univ.kiev.ua

Larisa T. Adzhubey, ORCID: 0000-0002-8103-9657, Taras Shevchenko National University of Kyiv, Ukraine, e-mail: adzhubey@ukr.net

Yuriy O. Naumenko, ORCID: 0000-0002-2631-1048, Taras Shevchenko National University of Kyiv, Ukraine, e-mail: yura.was.here@gmail.com

Mykhailo F. Makhno, ORCID: 0000-0002-5826-7408, Taras Shevchenko National University of Kyiv, Ukraine, e-mail: makhnom@gmail.com

ПРО ОДИН ПІДХІД ДО ЗАСТОСУВАННЯ ДРОБОВОГО АНАЛІЗУ ДЛЯ МОДЕЛЮВАННЯ ПРОЦЕСІВ ІНФОРМАЦІЙНОГО ПОШИРЕННЯ /

Є.В. Івохін, Л.Т. Аджубей, Ю.О. Науменко, М.Ф.Махно

Анотація. Розглянуто методику побудови моделі та метод знаходження розв'язків у задачі імітаційного моделювання процесу поширення інформації на основі використання крайової задачі для дробово-диференціального рівняння в частинних похідних. В основу покладено методику аналогій для моделювання процесів інформаційного поширення, яка базується на використанні особливостей дробового аналізу та дифузійного характеру процесів проникнення інформації. Запропоновано спосіб побудови гібридних моделей, що дозволяє враховувати зміни у часі граничних значень просторової змінної. Розглянуто однорідні та неоднорідні моделі дифузійних процесів, які дали змогу числено отримувати й аналізувати експериментальні дані для вирішення завдання моніторингу рівнів поширення інформації в соціальних групах.

Ключові слова: інформація, поширення, моделювання, диффузійні гібридні моделі, дробовий аналіз.

ОБ ОДНОМ ПОДХОДЕ К ИСПОЛЬЗОВАНИЮ ДРОБНОГО АНАЛИЗА ДЛЯ МОДЕЛИРОВАНИЯ ПРОЦЕССОВ ИНФОРМАЦИОННОГО РАСПРОСТРАНЕНИЯ / Е.В. Ивохин, Л.Т. Аджубей, Ю.А. Науменко, М.Ф. Махно

Аннотация. Рассмотрены методика построения модели и метод нахождения решений в задаче имитационного моделирования процесса распространения информации на основе использования краевой задачи для дробнодифференциального уравнения в частных производных. Предлагается использовать методику аналогий для моделирования процессов информационного распространения, которая базируется на использовании особенностей дробного анализа и диффузного характера процессов проникновения информации. Предложен способ построения гибридных моделей, позволяющий учитывать изменения во времени предельных значений пространственной переменной. Рассмотрены однородные и неоднородные модели диффузионных процессов, 
позволяющие численно получать и анализировать экспериментальные данные для решения задачи мониторинга уровней распространения информации в социальных группах.

Ключевые слова: информация, распространение, моделирование, диффузионные гибридные модели, дробный анализ.

\section{REFERENCES}

1. Yu.I. Babenko, Fractional Differentiation Method in Applied Problems of Heat and Mass Transfer. Sankt-Peterburg: NPO «Professional», 2009, 584 p.

2. V.V. Vasil'ev and L.A.Simak, Fractional Calculus and Approximation Methods in Modeling Dynamical Systems. Kyiv: NAS Ukraine, 2008, 256 p.

3. I. Petras, Fractional nonlinear systems: modeling, analysis and simulation. HEP, Springer, Nonlinear Physical Science, 2011, 235 p.

4. R.T. Sibatov and V.V. Uchaikin, "Fractional differential kinetics of charge transfer in disordered semiconductors", Semiconductor physics and technology, vol. 41, iss. 3, pp. 346-351, 2007.

5. K. Diethelm, N.J. Ford, A.D. Freed, and Yu. Luchko, "Algorithms for the fractional calculus: a selection of numerical methods", Comput. Methods Appl. Mech. Eng., vol. 194, pp. 743-773, 2005.

6. A.N. Korchagina and L.A. Merzhievskiy, "Numerical modeling of diffusion processes in fractal media", Scientific memories ZabSU, no. 3(50), pp. 53-59, 2013.

7. L.I. Moroz, "Numerical solution of one class of initial-boundary value problems for the fractional-order diffusion equation", Vestnik AmSU, iss. 85, pp. 3034, 2019.

8. R. Bellman, Mathematical methods in medicine. Singapore: World Scientific Pub. Co. Inc., 1983, 268 p.

9. A. Nowak and R.R. Vallacher, "Computational Models of Social Processes", Encyclopedia of Cognitive Science, pp. 81-84, 2006. doi: 10.1002/0470018860.s00639.

10. H. Quastler, The emergence of biological organization. New Haven and London: Yale University Press, 1964, 83 p.

11. H. von Scheel, M. Zakaria, and M. von Rosing, "Social Media and Business Process Management", The Complete Business Process Handbook. Body of Knowledge from Process Modeling to BPM, vol. I, pp. 381-398, 2015. doi: 10.1016/B978-0-12-7999593.00018-5.

12. R. Smith, Modelling Disease Ecology with Mathematics. Ottawa: American Institute of Mathematical Sciences, 2017, 291 p.

13. E.V. Ivokhin and L.T. Adzhubey, "About the use of diffusion process models for description of information extension dynamics", Scientific Bulletin of Uzhgorod University. Series of Mathematics and Informatics, no. 1(34), pp. 86-93, 2019. doi: 10.24144/26162019.1(34).

14. E.V. Ivokhin and Yu.A. Naumenko, "On Formalization of Information Dissemination Processes Based on Hybrid Diffusion Models", Journal of Automation and Information Sciences, vol. 50, no. 4, pp. 121-128, 2018. doi: 10.1615/JAutomatInfScien.v50.i7.70

15. E.V. Ivokhin, L.T. Adzhubey, and E.V. Gavrylenko, "On the Formalization of Dynamics in Information Processes on the Basis of Inhomogeneous One-Dimensional Diffusion Models", Journal of Automation and Information Sciences, vol. 51, no. 2, pp. 22-29, 2019. doi: 10.1615/JAutomatInfScien.v51.i2.30

16. E.V. Ivokhin and L.T. Adzhubey, "On the modeling of information distribution dynamics on the basis of homogeneous diffusion hybrid models", Scientific Bulletin of Uzhgorod University. Series of Mathematics and Informatics, no. 2(35), pp. 112-118, 2019.

17. E.V. Ivokhin, L.T. Adzhubey, E.V. Gavrylenko, and Yu.A. Naumenko, "Research of dynamics of information distribution processes based on diffusion hybrid models", Radio Electronics, Computer Science, Control, no. 2, pp. 129-136, 2020.

18. R.I. Parovik, P.P. Firsov, and E.O. Makarov, "Mathematical modeling of the fractal dimension of the geoenvironment", Vestnik of Kamchatka regional association UNC. Phys.-Math. Science, iss. 2(3), pp. 42-49, 2011.

19. E. Hairer, S.P. Norsett, and G. Wanner, Solving Ordinary Differential Equations I: Nonstiff Problems; (2nd ed.). Berlin: Springer-Verlag, 1993, 512 p. doi: 10.1007/978-3-540-78862-1.

20. B.M. Budak, A.A. Samarskiy, and A.N. Tikhonov, Task collection on mathematical physics. Moscow: GizTTL, 1956, 683 p. doi: 10.1016/C2013-0-05314-5. 